\title{
Trabalhando tópicos da geometria com o auxílio do Geoplano: uma experiência com alunos do sexto ano do Ensino Fundamental
}

\section{Working on geometry topics with the help of the Geoplano: an experience with sixth grade students}

Universidade do Eernando de Oliveira Freire Ensino, Pau dos Ferros, RN, Brasil https://orcid.org/0000-0002-6454-1098, fernando.ofreire@hotmail.com

Marcelo Nascimento de Morais Oliveira Universidade do Estado do Rio Grande do Norte (UERN), Programa de Pós-Graduação em Ensino, Pau dos Ferros, RN, Brasil https://orcid.org/0000-0002-2850-9437, marcelomnm1@gmail.com

Maria da Paz Cavalcante Universidade do Estado do Rio Grande do Norte (UERN), Programa de Pós-Graduação em Ensino, Pau dos Ferros, RN, Brasil https://orcid.org/0000-0003-0893-2411, mariapaz@uern.br

Valentim Alves Cavalcante Neto Universidade do Estado do Rio Grande do Norte (UERN), Programa de Pós-Graduação em Ensino, Pau dos Ferros, RN, Brasil https://orcid.org/0000-0002-6336-7438, Valentimalvesc@yahoo.com.br

\section{Informações do Artigo}

Como citar este artigo

FREIRE, Fernando de Oliveira; OLIVEIRA, Marcelo Nascimento de Morais;

CAVALCANTE, Maria da Paz; CAVALCANTE NETO, Valentim Alves. Trabalhando tópicos da geometria com o auxílio do Geoplano: uma experiência com alunos do sexto ano do Ensino Fundamental. REMAT: Revista

Eletrônica da Matemática, Bento

Gonçalves, RS, v. 7, n. 1, p. e2005, 25 mar. 2021. DOI:

https://doi.org/10.35819/remat2021v7i1id4554

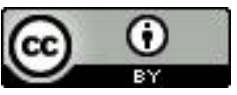

Histórico do Artigo

Submissão: 9 de setembro de 2020.

Aceite: 3 de dezembro de 2020 .

\section{Palavras-chave}

Geoplano

Geometria Plana

Figuras Geométricas

Aprendizagem

\section{Resumo}

O ensino de Matemática vem passando por mudanças significativas. Métodos tradicionais, antes aceitos, baseados na mera transmissão acrítica de conteúdos por meio de exercícios repetitivos e memorização de fórmulas, vêm sendo questionados em virtude de sua baixa contribuição para o desenvolvimento da aprendizagem do educando. Nessa esteira, o presente artigo tem como objetivo abordar o Geoplano como recurso didático no estudo de tópicos da geometria e analisar a desenvoltura dos alunos de uma turma de $6^{\circ}$ ano do Ensino Fundamental na aprendizagem dessa temática com o auxílio desse recurso. $\mathrm{Na}$ realização desse estudo de natureza qualitativa, utilizou-se da pesquisa-ação colaborativa considerando uma experiência vivenciada em uma turma participante. Os resultados revelam que houve avanços nos níveis de aprendizagem dos alunos no que se refere aos conceitos geométricos estudados. Constatou-se, ainda, o envolvimento dos educandos nas aulas, sendo possível perceber as potencialidades de aplicação do Geoplano como um recurso didático, principalmente no ensino de figuras planas, áreas, perímetro, semelhanças das figuras planas, ponto, reta e plano.
Keywords

Geoplane

Plane Geometry

Geometric Figures

Learning

\begin{abstract}
Mathematics teaching has undergone significant changes. Traditional methods, previously accepted, based on the mere uncritical transmission of content through repetitive exercises and memorization of formulas, have been questioned due to their low
\end{abstract}


contribution to the development of learning. In this context, the present article aims at using the Geoplano as a didactic tool in the work whit geometry topics and at analyzing the resourcefulness of the resourcefulness of a class of 6th grade students in an elementary school an elementary school while learning said topics using the aid of this resource. In conducting this qualitative study, we resorted to collaborative action research, where we draw on the experience of a participating classroom. The results show that there have been advances in students' learning levels regarding the studied geometric concepts. the involvement of students in classes was also verified, being possible to perceive the potentialities of application of the Geoplano as a didactic resource, mainly in the teaching of flat figures, areas, perimeter, similarities to flat figures, point, line and flat.

\section{Introdução}

O ensino de Matemática vem passando por mudanças significativas. Métodos tradicionais, antes aceitos, baseados na transmissão acrítica dos conteúdos por meio de exercícios repetitivos e memorização de fórmulas, vêm sendo questionados em virtude de sua baixa contribuição para o desenvolvimento da aprendizagem.

A tônica desse debate tem sido a busca de melhores recursos pedagógicos para o ensino e aprendizagem da Matemática com o intuito de contribuir para o alcance de melhores níveis de aprendizagem por parte dos educandos. Nessa conjuntura, o movimento educacional denominado Educação Matemática, que teve início nos anos de 1970, vem empreendendo estratégias alternativas para o ensino de Matemática que têm como fim uma aprendizagem mais consistente. Surgem, desse modo várias vertentes desse movimento como, por exemplo, a etnomatemática, a modelagem matemática, a história da matemática, os jogos matemáticos, Tecnologia da Informação e Comunicação (TICs), e o uso de materiais manipuláveis ou concretos (BRASIL, 1997).

Esse movimento tem potencializado a abordagem da Matemática como uma Ciência dinâmica, interativa e próxima da realidade dos educandos. Frente ao cenário educacional brasileiro, a busca por novos caminhos para o ensino de Matemática se mostram necessários e urgentes, pois, de acordo com o Programa Internacional de Avaliação de Estudantes (PISA), o Brasil apresenta baixa proficiência em Matemática, levando o país a ocupar as últimas posições em níveis de aprendizagem dessa disciplina quando comparado a outros países da América Latina (BRASIL, 2019).

Dessa forma, destacamos a viabilidade do uso de materiais manipuláveis, foco deste trabalho, uma vez que esses recursos permitem o desenvolvimento do raciocínio lógico, matemático e espacial, fazendo com que os educandos evoluam do estágio do saber concreto para formalização de conceitos matemáticos.

Dentre os materiais didáticos manipuláveis, ressaltamos o Geoplano como um instrumento capaz de viabilizar, de forma didática e intuitiva, o trabalho com tópicos da geometria tais como a 
formação de figuras planas, cálculo de áreas e perímetro, semelhanças das figuras planas, ponto, reta, plano, entre outros conteúdos.

Diante do exposto, o presente trabalho tem como objetivo abordar o Geoplano como recurso didático no estudo de tópicos da geometria e analisar a desenvoltura dos alunos de uma turma de $6^{\circ}$ ano do Ensino Fundamental na aprendizagem dessa temática com o auxílio desse recurso.

\section{Materiais manipuláveis no ensino de Matemática: caso do Geoplano}

Como afirmam Leal e Chieregatto (2018), as concepções de aprendizagem sofreram grandes alterações na transição do século XIX para o século XX. Os estudantes deixaram de ser vistos como depósito de informações e passaram a ter suas experiências consideradas em seu processo de formação.

No tocante ao ensino da Matemática, Rodrigues e Gazire (2012) destacam que, tradicionalmente, o ensino dessa disciplina esteve associado ao estudo de conceitos, teorias e fórmulas pautados apenas no abstrato. Como alternativa a essa realidade, recursos pedagógicos vêm sendo empreendidos no intuito de facilitar o processo de construção do conhecimento, tornando possível vislumbrar, de modo concreto/visual, alguns conceitos matemáticos.

Dentre os recursos pedagógicos para o ensino da Matemática, tem-se o uso de materiais manipuláveis, que, na concepção de Reys (1971 apud NACARATO, 2005, p. 3), são "objetos ou coisas que o estudante é capaz de sentir, tocar, manipular e movimentar. Podem ser objetos reais que têm aplicação no dia-a-dia ou podem ser objetos que são usados para representar uma ideia". Desse modo, os materiais manipuláveis podem propiciar uma aprendizagem mais ativa e dinâmica, permitindo uma maior interação do estudante com o conteúdo em estudoe contribuindo significativamente para a construção efetiva do saber.

Nessa esteira, com a finalidade de auxiliar estudantes e professores no estudo da geometria, sobretudo, plana, o educador inglês Caleb Gattegno ,do Instituto de Educação da Universidade de Londres, idealizou o Geoplano (KNIJNIK; BASSO; KLÜSENER, 1996). Esse recurso pedagógico consiste em um plano feito de madeira ou outro tipo de material composto de pregos ou pinos dispostos de forma espaçadamente igualitária ao longo do plano.

De acordo com Silva e Souza (2016, p. 97), esse recurso “[...] permite ao aluno representar de forma concreta as ideias abstratas das mais diversas formas geométricas, constituindo-se num apoio aos processos de aprendizagem, fortalecendo os níveis de conhecimento geométrico do aluno".

Estudos como os de Ferrugine et al. (2017) e Freire (2018) apontam o Geoplano como uma forma interativa no ensino de figuras geométricas a estudantes do Ensino Fundamental e Médio. Segundo esses estudos, o trabalho com o Geoplano possibilita a assimilação visual das formas geométricas e a contribuição para resolução de exercícios aplicados em sala de aula, além 
da interatividade no ambiente de aprendizagem. Em face a esses trabalhos, aludimos à efetividade e à adaptabilidade do uso desse recurso manipulável nos diferentes níveis de ensino da Educação Básica.

Cabe destacar que há diversos tipos de geoplanos, variando conforme a sua utilidade para a abordagem de conteúdos matemáticos (MACHADO, 2004). Neste trabalho, usaremos o Geoplano em formato quadricular, conforme Figura 1, onde os pregos/pinos estão dispostos de forma igualmente espaçada.

Figura 1 - Geoplano Quadricular.

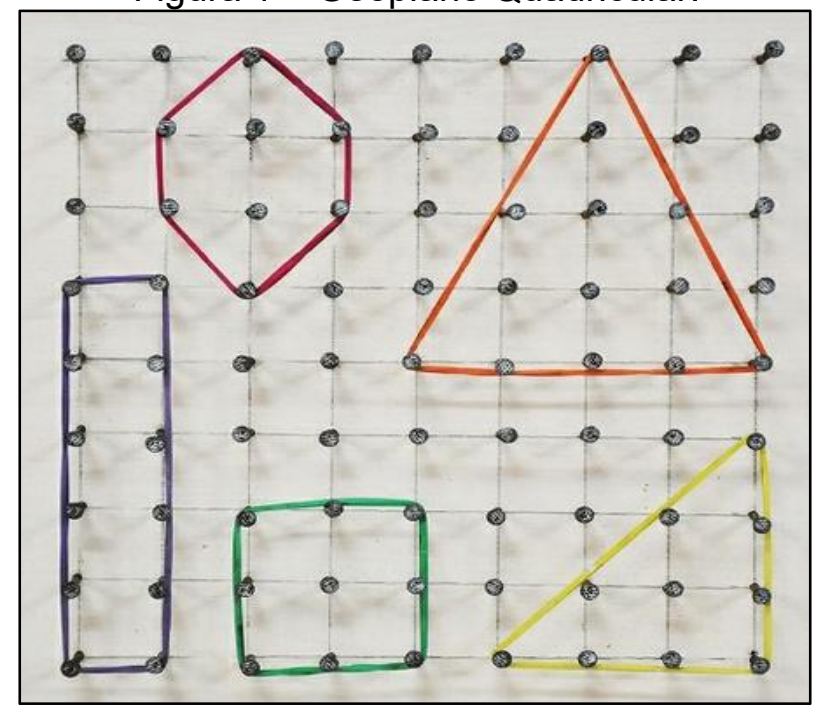

Fonte: Dados da pesquisa (2018).

Posto isso, na seção seguinte descrevemos a metodologia utilizada na construção deste trabalho.

\section{Metodologia}

A pesquisa foi realizada com alunos da turma do $6^{\circ}$ ano do Ensino Fundamental em uma Escola Estadual no Rio Grande do Norte no Alto Oeste Potiguar. A referida turma estava composta por 40 alunos com uma faixa etária entre dez e quatorze anos de idade.

Quanto à abordagem metodológica, a pesquisa enquadra-se no tipo qualitativa. A escolha dessa abordagem se deve ao fato desta procurar observar e compreender as ações, fatos e resultados de forma mais abrangente, pondo as ações dos sujeitos investigados em evidência (OLIVEIRA, 2012).

Quanto à intervenção no ambiente escolar, foram promovidos dois encontros, de uma hora e meia cada, durante o mês de outubro/2018, quando adotamos no percurso a pesquisa-ação colaborativa, devido às suas contribuições tanto para o trabalho docente proposto quanto para a obtenção dos dados da pesquisa.

$\mathrm{Na}$ pesquisa-ação colaborativa, muito comum em situações que envolvem a dinâmica escolar, os conhecimentos ali produzidos (fruto da interação professor-alunos) são fontes para o 
trabalho investigativo, ao mesmo tempo em que oportunizam reflexões pedagógicas para um melhor fazer docente (ESTEBAN, 2010).

Nesse prisma, no primeiro encontro, nos apresentamos como equipe de pesquisadores, bem como o trabalho a ser realizado. Em seguida, aplicamos a primeira parte do questionário, contendo questões abertas e fechadas que discorriam sobre a temática da geometria. Depois, realizamos uma breve exposição dialogada com os alunos revendo tópicos básicos dessa temática, uma vez que a turma já tinha trabalhado com geometria no segundo bimestre. Por fim, foi apresentado o Geoplano para a turma participante com a consequente realização de um primeiro grupo de atividades envolvendo tópicos de geometria plana: entes primitivos da geometria e construções de polígonos.

No segundo encontro, com os alunos já familiarizados com o Geoplano, exploramos o segundo grupo de atividades, contemplando os temas: áreas e perímetros das figuras planas e semelhança das figuras. Ao final, aplicamos um segundo questionário e encerramos os trabalhos. Concluídas a intervenção e a coleta dos dados, recorremos também à pesquisa bibliográfica atinente à técnica da triangulação ${ }^{1}$ para procedermos com a organização e análise dos dados, culminando com a redação deste artigo.

\section{Resultados e discussão}

O trabalho de intervenção na turma participante foi realizado em dois encontros: o primeiro no dia 16 de outubro de 2018 e o segundo no dia 23 de outubro de 2018. Dos 40 alunos da turma, 38 participaram do primeiro encontro, já no segundo e último encontro o registro foi de 31 participantes.

Quando aplicamos o primeiro questionário, tivemos como objetivo identificar a compreensão dos alunos no tocante a tópicos básicos da geometria.

Instados a descreverem quais os seus entendimentos acerca da geometria, observamos que grande parte dos alunos conseguia reconhecer ou relacioná-la com as formas geométricas presentes no dia a dia, mesmo com dificuldades de defini-las matematicamente. O Gráfico 1 mostra o resultado dessa primeira indagação, de modo que, por se tratar de uma questão aberta, os resultados foram agrupados por proximidade das respostas.

Gráfico 1 - Com base no seu conhecimento, o que você compreende por Geometria?

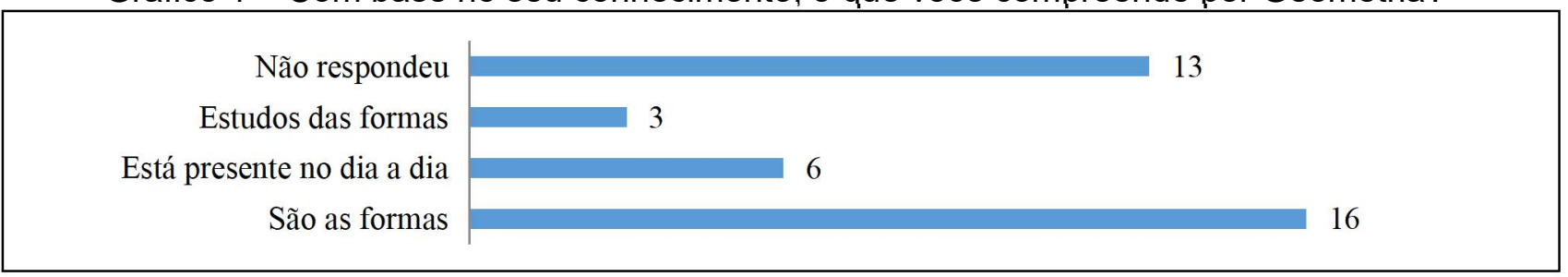

Fonte: Dados da pesquisa (2018).

\footnotetext{
1 Técnica utilizada para a validação e a convergência dos dados considerando suas diversas fontes de captação (ZAPPELLINI; FEUERSCHÜTTE, 2015).
} 
Vejamos que majoritariamente, $76 \%$ dos alunos associou a geometria às formas e ao estudo delas. Essa concepção vem ao encontro de Ferreira (1999, p. 983), que define Geometria como: "Ciência que investiga as formas e as dimensões dos seres matemáticos", ou seja, um ramo da Matemática que estuda as formas, plana e espacial, com as suas propriedades, ou ainda, ramo da Matemática que estuda a extensão e as propriedades das figuras (geometria Plana) e dos sólidos (geometria no espaço).

Etimologicamente, a palavra geometria vem do grego (geo) e (metria), que significa medição da terra (SILVA, 2020). A partir dessa definição, reconhecer o que está presente no mundo concreto facilitará o avanço na construção de conceitos geométricos.

Os conhecimentos geométricos constituem parte importante do currículo de Matemática no Ensino Fundamental. Os Parâmetros Curriculares Nacionais (PCNs) destacam, dentre outras coisas, a importância desses conhecimentos e dessa etapa de ensino no processo de formação dos estudantes. Segundo os PCNs:

Os conceitos geométricos constituem parte importante do currículo de Matemática no Ensino Fundamental, porque, por meio deles, o aluno desenvolve um tipo especial de pensamento que lhe permite compreender, descrever e representar, de forma organizada, o mundo em que vive. O trabalho com noções geométricas contribui para a aprendizagem de números e medidas, pois estimula a criança a observar, perceber semelhanças e diferenças, identificar regularidades e viceversa (BRASIL, 1997, p. 39).

Esse documento destaca ainda que o ensino de Geometria, principalmente nos anos iniciais, deve possibilitar que o aluno estabeleça pontos de referência que the permitam se situar e se posicionar no espaço. Além disso, perceber semelhanças e diferenças entre objetos no espaço, identificar e representar as formas e suas dimensões são habilidades essenciais.

Sob essa premissa, desenvolvemos um conjunto de atividades com o uso do Geoplano buscando não só auxiliar na consolidação da aprendizagem do conteúdo já abordado na turma pela professora colaboradora, mas revê-lo,dessa vez, sob uma perspectiva dinâmica, concreta e interativa.

Ainda no primeiro encontro, também indagamos os alunos se os professores utilizaram no ensino de geometria algum recurso auxiliar a exemplo de jogos, vídeos, programas de computador, materiais concretos, materiais manipulativos, ou outras atividades práticas.

Gráfico 2 - Utilização de recursos pelos professores, no ensino de geometria.

Os professores utilizam algum recurso auxiliar para o ensino de geometria?

$20 \%$

- Sim Não

$80 \%$

Fonte: Dados da pesquisa (2018) 
Esses dados coadunam com nosso pensamento inicial de que muitos professores têm refletido e buscado estratégias facilitadoras que visam atingir melhores níveis de aprendizagem em Matemática num movimento crescente que possibilite aos estudantes participar ativamente do processo de construção do conhecimento.

Nessa direção, Paraná (2008, p. 45) aponta a relevância da criação e adoção de estratégias que proporcionem ao aluno atribuir sentido e construir significados às ideias matemáticas de modo a tornar-se capaz de estabelecer relações, justificar, analisar, discutir e criar.

Assim posto, ao considerarmos a importância do uso do recurso Geoplano no âmbito de abordagem dos conteúdos matemáticos, o presente estudo considera o uso desse recurso como um meio facilitador para o processo de ensino e aprendizagem de temáticas referentes à geometria plana.

Ao solicitarmos que os alunos apresentassem sugestões de metodologias e/ou de recursos para as aulas de geometria, as principais respostas dos estudantes foram sintetizadas no Gráfico 3.

Gráfico 3 - Metodologias e/ou recursos sugeridos pelos alunos participantes para as aulas de geometria.

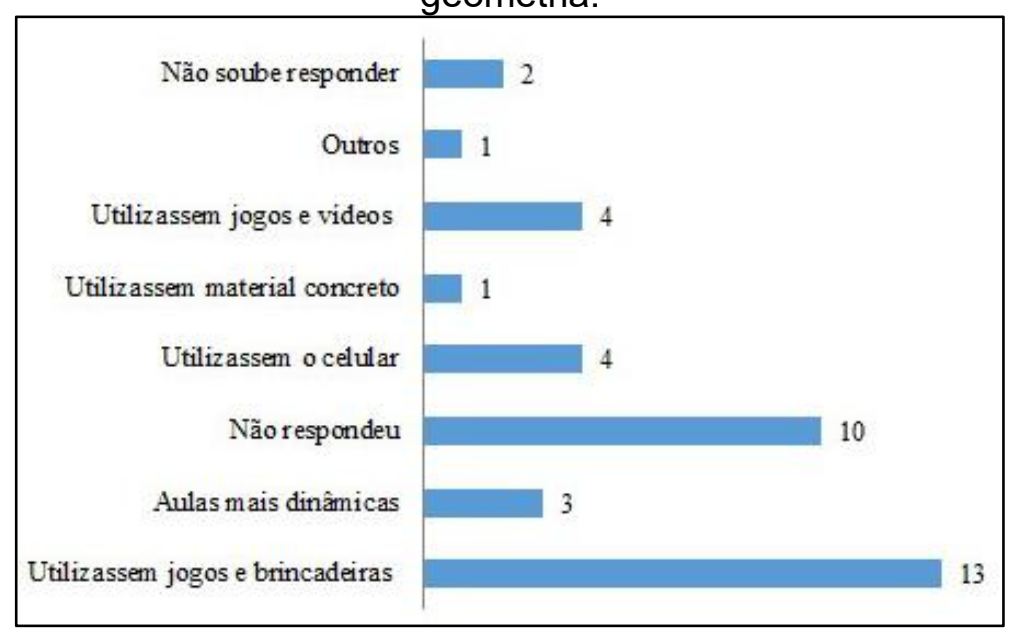

Fonte: Dados da pesquisa (2018).

Constatamos que $44 \%$ dos alunos apontaram como alternativa para tornar as aulas de geometria mais atrativas o uso de jogos e brincadeiras. Assim, é possível percebermos a importância do lúdico no processo de ensino e aprendizagem da Matemática, o que está alinhado com os Parâmetros Curriculares de Matemática para o Ensino Fundamental, de modo que: "[...] a participação em jogos de grupo também representa uma conquista cognitiva, emocional, moral e social para a criança e um estímulo para o desenvolvimento do seu raciocínio lógico" (BRASIL, 1997, p. 36).

Diante dessa constatação, readequamos algumas das atividades propostas para o segundo encontro, acrescentando o lúdico ao trabalho de intervenção. Vencida essa etapa inicial do trabalho de intervenção, consideramos as dificuldades apresentadas pelos alunos e partimos 
para uma exposição dialogada sobre a geometria e seus entes primitivos (ponto, reta e plano), classificação das figuras geométricas (figuras planas e espaciais) e, por fim, a formação de alguns polígonos com o auxílio do Geoplano.

A escolha da temática justifica-se pelo fato da geometria se constituir como um campo fértil para se trabalhar com situações-problema e se constituir por ser um tema pelo qual os alunos costumam se interessar naturalmente, possibilitando abordar o trabalho com números e medidas, a observação e identificação de semelhanças e diferenças das formas (BRASIL, 1997).

Nessa etapa, foram constatadas muitas dificuldades dos alunos em reconhecer os itens basilares da Geometria (o ponto, a reta e o plano). Talvez pela falta de prática em exercitar a abstração matemática², expressões como "sei lá", "nunca vi isso", "não lembro" eram comuns nas diversas falas que ecoavam na sala de aula. No entanto, quando passamos a associá-los aos elementos do Geoplano, os alunos passaram a compreender a noção intuitiva de ponto (ao associar essa definição à ponta do prego), a reta (foi associada a vários pregos alinhados) e de plano (os diversos pregos que compõe o Geoplano). A ideia era chegar à aprendizagem desses temas pelo caminho inverso: do concreto para o abstrato.

Posteriormente, os alunos foram indagados sobre a classificação das figuras em planas e em espaciais. Quanto às figuras planas, eles não tiveram dificuldades. Um dos discentes verbalizou: "[...] São figuras que estão no plano", sendo aceito pelo demais.

De fato, as figuras geométricas planas são aquelas que estão todas contidas no plano, diferentemente das espaciais que excedem do plano, tais como os sólidos geométricos (cubo, paralelepípedo, esfera, cone, entre outras). Com isso, pedimos para que os alunos respondessem à questão 4, apresentada na Figura 2, da lista de atividades proposta e verificamos que os participantes não tiveram maiores dificuldades em nominar as figuras expostas.

Figura 2 - Questão 4 da lista de atividades.

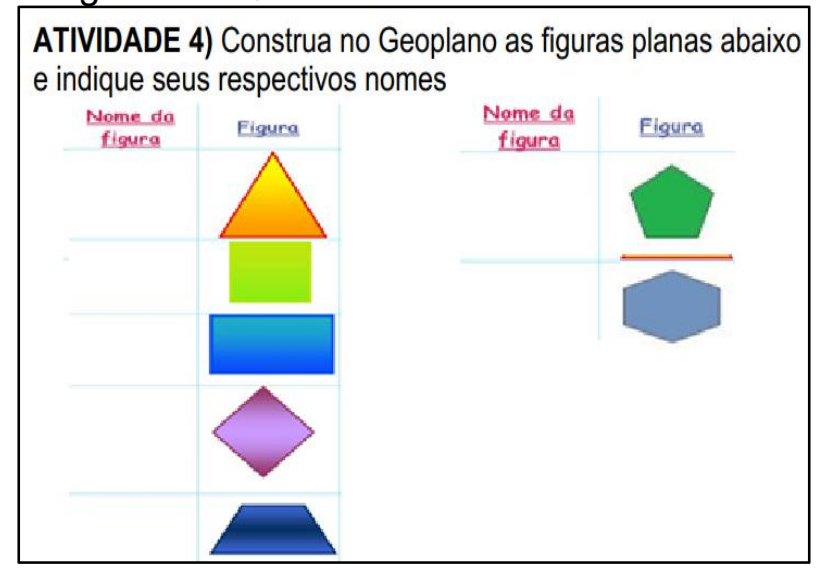

Fonte: Dados da pesquisa (2018).

Dando sequência ao primeiro dia de atividades, disponibilizamos os Geoplanos (já construídos anteriormente) para que os alunos pudessem construir as figuras geométricas em

${ }^{2}$ Exercício lógico estruturado no universo exclusivo da mente que independe da experiência concreta (FOSSA, 1998). 
sala de aula. Dada a limitação de tempo e o excessivo número de alunos, readequamos algumas das atividades propostas de forma que fossem priorizadas as atividades que contemplassem os conteúdos mais basilares da geometria, a saber: áreas, perímetros e semelhanças.

Foi perceptível o entusiasmo dos alunos com o manuseio do Geoplano - algo que em um primeiro momento parecia ser "temido" por esses estudantes, visto que muitos desconheciam esse recurso. Ao final da atividade, configurou-se um cenário de interatividade entre alunos e dinamicidade na aprendizagem, possibilitada pelo uso desse material manipulável.

Prosseguindo com o trabalho de intervenção, o segundo encontro foi dedicado às atividades de obtenção numérica e compreensão dos conceitos de áreas, perímetros e semelhanças das figuras planas. Para essa etapa da intervenção, a turma foi dividida em grupos de oito alunos.

Diante da questão 7, apresentada na Figura 3, da lista de atividades, os alunos foram solicitados a determinar o perímetro das figuras expostas. Quando questionados acerca do conceito de perímetro, eles identificaram como sendo "a soma dos lados", como intuitivamente é compreendido de forma empírica pelo público em geral. Fato esse que nos surpreendeu positivamente, pois, de fato, ampliando essa noção intuitiva, podemos depreender perímetro como o contorno, expresso numericamente em uma medida de comprimento linear, de uma figura geométrica plana.

Figura 3 - Questão 7 da lista de atividades.

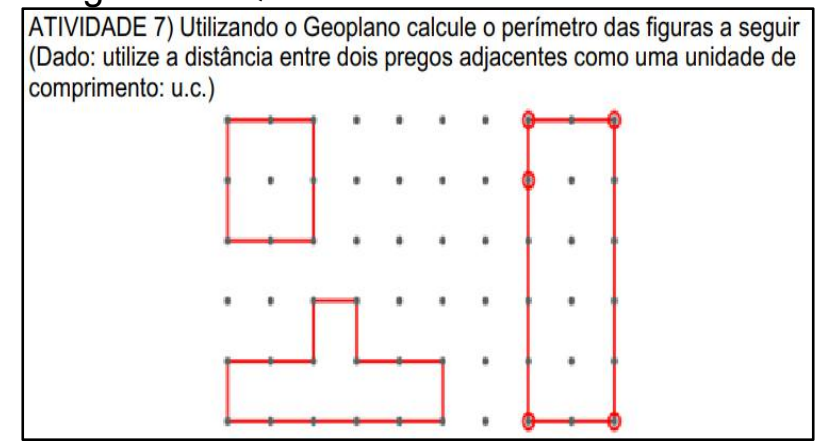

Fonte: Dados da pesquisa (2018).

Conforme a Figura 3, tomando como referência que a distância entre dois pregos equivalem a uma unidade de comprimento (u.c.), logo foi possível os alunos responderem que o quadrado tem um perímetro de 8 u.c., o retângulo 14 u.c., e que a figura de sete lados tem um perímetro também de 14 u.c. Destacamos que a validação das respostas apresentadas era realizada com a contagem das unidades de medida de comprimento de cada figura exposta.

Em seguida, os alunos foram provocados a realizar a questão seguinte, conforme Figura 4, também envolvendo o conceito de perímetro, só que dessa vez envolvendo figuras contendo lados com inclinações diferentes de 90 graus. 
Figura 4 - Questão 8 da lista de atividades.

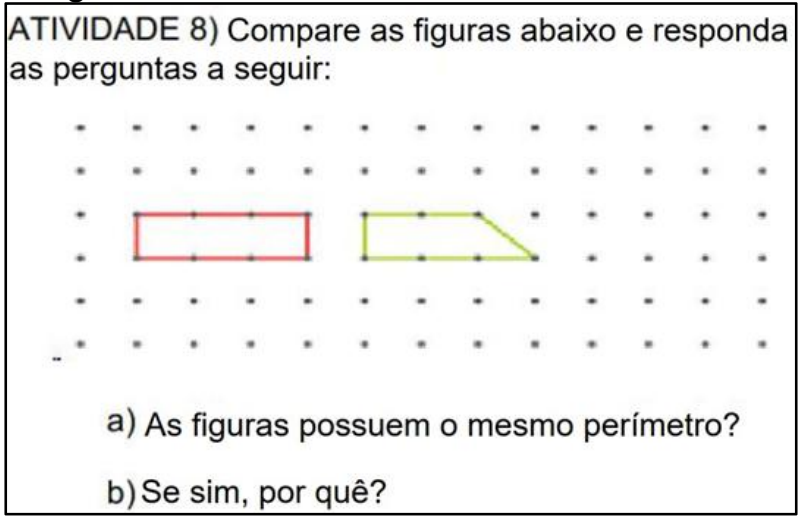

Fonte: Dados da pesquisa (2018).

Mais uma vez nos surpreendeu positivamente que quase a totalidade dos participantes respondeu que as figuras não detinham o mesmo perímetro, e que o lado não paralelo do trapézio apresenta uma medida linear maior que o lado oposto. Para chegar a essa constatação, antes de justificá-la com o rigor matemático que a questão exige, foi primordial a percepção visual dos alunos; muitos deduziram através do olhar, outros utilizaram alguns recursos como régua, ou mesmo o diâmetro do lápis, para comparar a medida do lado não paralelo do trapézio com o lado oposto. Vejamos a resposta de um dos alunos participantes na Figura 5.

Figura 5 - Resposta de um aluno participante.

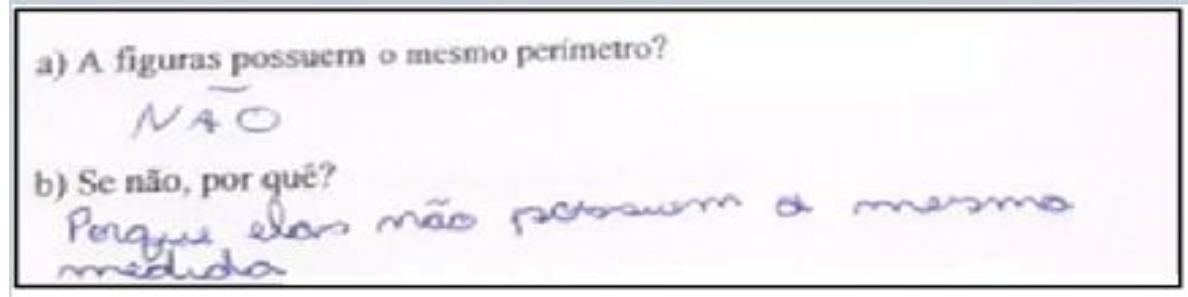

Fonte: Dados da pesquisa (2018).

Esse aluno, assim como grande parte dos alunos participantes, chegou à constatação de que esse lado detinha uma medida maior que o lado oposto, ou seja, que era maior que 1 u.c. $A$ despeito desse fato, Brasil (1997) enfatiza que a percepção visual é o passo inicial para o pensamento geométrico. O documento ainda destaca que "[...] as figuras geométricas são reconhecidas por suas formas, por sua aparência física, em sua totalidade, e não por suas partes ou propriedades" (BRASIL, 1997, p. 82).

Ainda em relação à questão em tela, matematicamente, o fato pode ser justificado através do Teorema de Pitágoras, o qual afirma que o quadrado da hipotenusa é igual à soma dos quadrados dos catetos. Sendo os catetos medindo uma u.c., logo, a medida da diagonal medirá aproximadamente 1,4 u.c.

Dando sequência, os alunos puderam manipular e explorar livremente o Geoplano para determinar os perímetros de outras figuras sugeridas pelos pesquisadores. Nesse momento, 
foram oportunizadas a ludicidade e a competitividade com uma breve gincana entre os grupos, sendo premiados os que detivessem maior número de acertos das questões sugeridas.

A proposta seguinte foi a abordagem do conceito de áreas das figuras. Com os alunos já familiarizados com o Geoplano, ficou mais fácil explorar a temática, sendo a área compreendida como a medida da superfície ocupada por uma figura plana. Em outras palavras, todo o espaço interno da região delimita de uma forma plana, sendo essa medida expressa em unidades de área (u.a.).

Assim, tomando o Geoplano como referência, cada "quadradinho" dele possui uma u.a., ou seja, para calcular a área de uma figura, é só verificar quantos desses quadradinhos cabem dentro da figura, conforme Figura 6.

Figura 6 - Representação da área e uma figura plana.

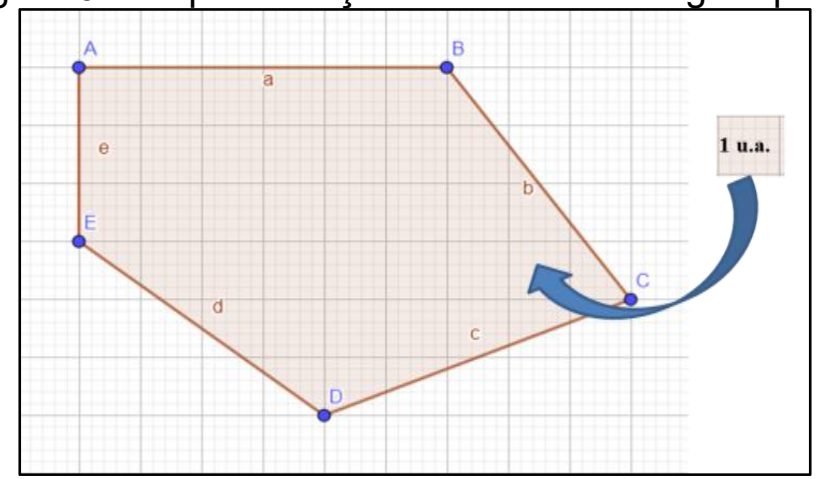

Fonte: Geogebra Classic (2018).

Feita essa abordagem conceitual, partimos para a resolução da questão 10 da lista de atividades, conforme Figura 7.

Figura 7 - Questão 10 da lista de atividades.

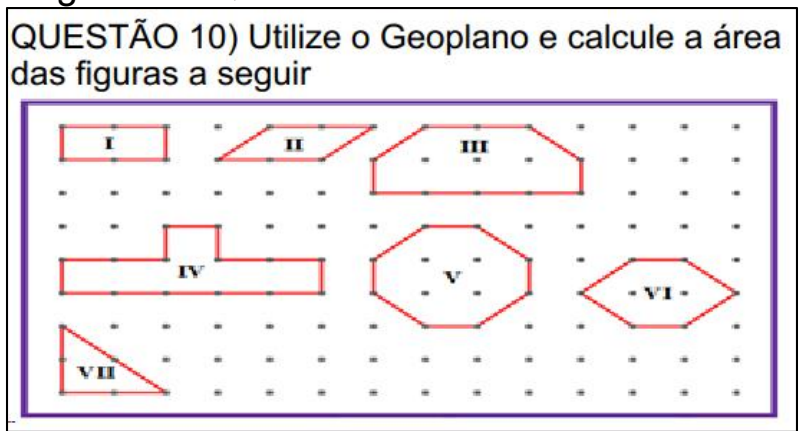

Fonte: Dados da pesquisa (2018).

Em face à atividade proposta, os alunos não tiveram dificuldades em determinar as áreas das figuras geométricas apresentadas. De imediato, eles determinaram as áreas das formas I e IV por serem formas mais bem definidas. Quanto às demais formas, os alunos se utilizaram mais uma vez da percepção visual para inferir que os lados formados por duas diagonais valiam a metade de uma u.a.

Nessa conjuntura, o Geoplano se consolida como recurso que estimula os alunos a resolverem problemas, aumentando a curiosidade na busca de solucioná-los, como também 
possibilita traçar caminhos e procedimentos para o fortalecimento do pensamento geométrico (PARANÁ, 2013).

Cabe pontuar que em nenhum momento foram tratadas as fórmulas matemáticas para determinação das áreas das formas geométricas. Preferimos que os alunos desenvolvessem a concepção intuitiva de áreas, visando uma maior apropriação da aprendizagem da temática, possibilitando que, em situações futuras, possam aplicar as fórmulas já com o conceito de área consolidado.

A última temática abordada foi a semelhança de figuras, que é compreendida como o estudo de figuras que possuem ângulos correspondentes congruentes e lados correspondentes proporcionais. Devido à limitação do tempo, optamos por abordar apenas o aspecto conceitual e sua aplicação no Geoplano, não adentrando na totalidade da temática. Entretanto, mesmo diante dessas limitações de tempo, os alunos participantes foram capazes de compreender os conteúdos trabalhados. Na questão 11 do caderno de atividades (Figura 8) eles puderam constatar que as figuras respeitam uma proporção bem definida $\left(\frac{2}{4}=\frac{3}{6}\right)$ entre os lados correspondentes:

Figura 8 - Questão 11 da lista de atividades.

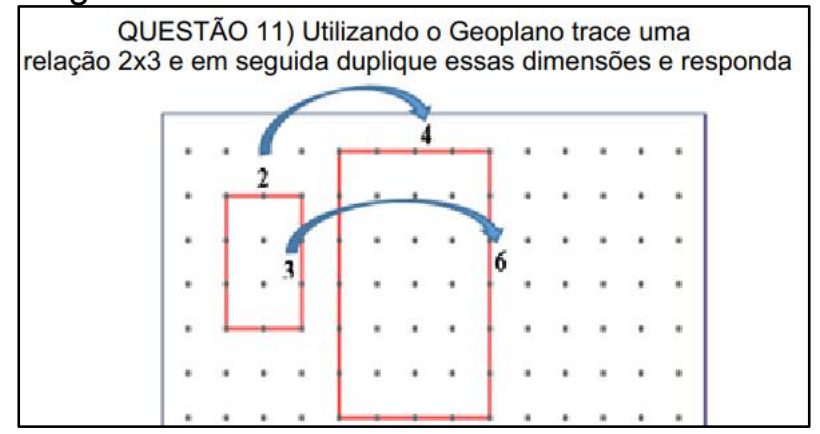

Fonte: Dados da pesquisa (2018).

A proposta da utilização do Geoplano para trabalhar conceitos de geometria na referida turma do Ensino Fundamental apresentou os seguintes resultados: foi constatado que os alunos demonstraram facilidade no desenvolvimento das atividades propostas, bem como na aprendizagem dos conceitos abordados em sala relacionados a geometria. Além disso, durante o desenvolvimento do trabalho em sala de aula, foi possível observar o envolvimento dos estudantes e seu interesse nas aulas. Assim, identificamos, por meio de um questionamento aos participantes (Gráfico 4), se o recurso utilizado (Geoplano) contribui significativamente no processo de aprendizagem dos conteúdos abordados.

Gráfico 4 - Resposta dos estudantes à pergunta: O Geoplano contribuiu para melhor compreender o estudo da geometria plana?

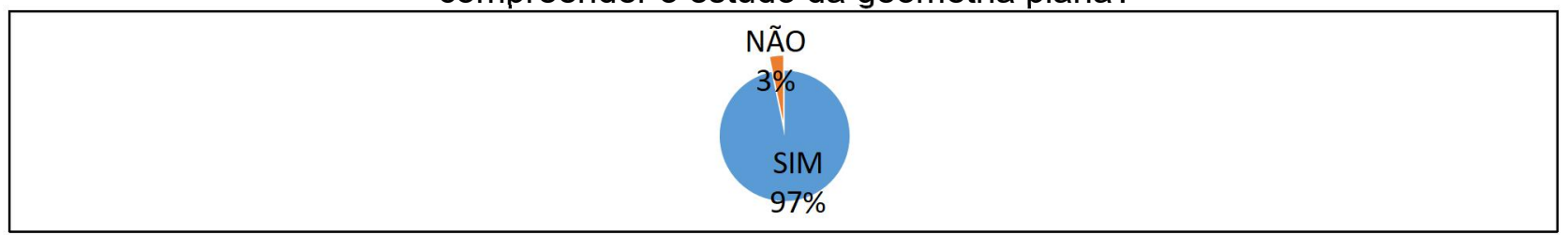

Fonte: Dados da pesquisa (2018). 
Esse resultado demonstra que, quando lançamos mão de estratégias metodológicas e recursos facilitadores da aprendizagem, fazendo com que o aluno vivencie a concretude daquela disciplina e/ou conteúdo, a aprendizagem é acompanhada de significado e sentido. Cabe destacar, ainda, que $48 \%$ dos alunos não conheciam ou nunca utilizaram o Geoplano em suas atividades de estudos da geometria plana.

\section{Considerações finais}

Visando alcançar melhores níveis de aprendizagem em Matemática, desde os anos de 1970, o movimento de Educação Matemática, composto por pesquisadores e educadores matemáticos, vem empreendendo esforços continuamente nessa trilha, fomentando, discutindo e refletindo sobre práticas pedagógicas alternativas que levem a abordar a Matemática de forma viva e interativa ao alcance dos alunos da formação básica.

Nessa perspectiva, os materiais manipuláveis (concretos/didáticos) têm se revelado eficazes na busca dessa empreitada, uma vez que oportunizam aos alunos, por meio da manipulação desses recursos, chegarem à matematização dos conteúdos tratados em sala de aula. Nesse escopo, foi trabalhado o Geoplano quadricular com a turma em questão para o desenvolvimento de tópicos de conteúdos da geometria plana.

Nessa direção, o presente trabalho ressalta a importância do uso de materiais manipuláveis, como o Geoplano, para a abordagem de tópicos basilares da geometria plana, proporcionando ao estudante se apresentar mais ativo na construção do seu conhecimento.

Assim, obtivemos resultados relativos à facilidade de desenvolvimento das atividades e da compreensão dos conceitos envolvidos, alcançando maior interesse e participação dos discentes nas aulas, sendo possível perceber as potencialidades de aplicação do Geoplano, principalmente para o ensino de figuras planas, áreas, perímetro, semelhanças das figuras planas, ponto, reta e plano.

Cabe destacar que foram perceptíveis as contribuições dessa intervenção pedagógica, pois $97 \%$ dos alunos participantes conseguiram desenvolver as atividades propostas, demonstrando avanços significativos na aprendizagem de conteúdos que julgavam difíceis, encontrando, desse modo, respostas e entendimentos para os diversos problemas geométricos abordados.

Este trabalho soma a outros, como os desenvolvidos por Ferrugine et al. (2017) e Freire (2018), que destacam o uso do Geoplano como instrumento que proporciona um ambiente interativo, capaz de auxiliar na resolução dos problemas propostos de forma didática. Abrindo, assim, espaço para mais essa reflexão: o interesse demonstrado pelos alunos para com o lúdico e a presença do ludico no ensinar e aprender Geometria por meio do Geoplano.

Por fim, ressaltamos que não é o intuito desse estudo esgotar as possibilidades referentes ao uso do Geoplano, mas reforçar a sua viabilidade para o trabalho em sala de aula, apontando-o 
como recurso pedagógico relevante para o professor de Matemática no ensino de Geometria, já que esse recurso possibilita uma variedade de experiências geométricas, tais como: realizar aferições, conjecturas, relações e estabelecer simetrias.

Em face ao exposto, no início da realização deste trabalho, os alunos possuíam muitas dificuldades com o conteúdo abordado, não sabiam onde nem como aplicar ou relacionar tal conhecimento. Então, proporcionar metodologias de ensino, com uso de materiais didáticos manipuláveis, facilita a compreensão de muitas situações e conteúdos desafiadores encontrados, diariamente, pelos alunos e é um dos caminhos que precisa ser trilhado, cada vez mais, pelos professores de Matemática.

\section{Referências}

BRASIL. Parâmetros Curriculares Nacionais: Matemática. Brasília: MEC/SEF, 1997.

BRASIL. Instituto Nacional de Estudos e Pesquisas Educacionais Anísio Teixeira (Inep). Relatório Brasil no PISA 2018: versão preliminar. Brasília, 2019. Disponível em:

http://download.inep.gov.br/acoes internacionais/pisa/documentos/2019/relatorio PISA 2018 prel iminar.pdf. Acesso em: 2 nov. 2020.

ESTEBAN, M. P. S. Pesquisa qualitativa em educação: fundamentos e tradições. Porto Alegre: AMGH, 2010.

FERREIRA, A. B. H. Novo dicionário Aurélio da Língua Portuguesa. 2. ed. Curitiba: Nova Fronteira, 1999.

FERRUGINE, S. S.; GUIMARÃES, S. S.; SOUZA, R. L. C. de; SOUZA, L. R. de; CASTRO, C. O., S. S. Geoplano: Uma forma interativa de aprender. In: CONGRESSO NACIONAL DE EDUCAÇÃO (CONEDU), 4., 2017, João Pessoa, PB. Anais [...]. Campina Grande: Realize Editora, 2017. Disponível em: https://editorarealize.com.br/artigo/visualizar/37092. Acesso em: 2 nov. 2020.

FOSSA, J. A. Teoria intuicionista da educação matemática. Natal: UFRN, 1998.

FREIRE, A. F.; RODRIGUES, F. S.; AQUINO, M. R. S.; SOARES, M. V.; GOIS, D. D. P. de; VIANA, J. D. O uso do Geoplano no ensino de geometria: cálculo de área e perímetro. Revista Científica Multidisciplinar Núcleo do Conhecimento, v. 3, ed. 6, ano 3, p. 119-135, jun. 2018. Disponível em: https://www.nucleodoconhecimento.com.br/matematica/calculo-de-area-eperimetro. Acesso em: 2 nov. 2020.

KNIJNIK, G.; BASSO, M. V.; KLÜSENER, R. Aprendendo e ensinando Matemática com o Geoplano. 2. ed. Ijuí, RS: Unijuí, 1996.

LEAL, M. C.; CHIEREGATTO, L. C. Um estudo bibliográfico sobre a influência das práticas de laboratório para o ensino de Ciências e Matemática: uma relação professor/aluno. Revista de Comunicação Científica, Juara, v. 3, n. 1, p. 67-78, jul./dez. 2018. Disponível em:

https://periodicos.unemat.br/index.php/rcc/article/view/3096. Acesso em: 22 mar. 2021.

MACHADO, R. M. Minicurso: Explorando o Geoplano. In: BIENAL DA SOCIEDADE BRASILEIRA DE MATEMÁTICA, 2., 25 a 29 out. 2004, Salvador. Anais [...]. Salvador: UFBA, Instituto de Matemática. Disponível em: http://www.bienasbm.ufba.br/M11.pdf. Acesso em: 12 nov. 2020. 
NACARATO, A. M. Eu trabalho primeiro no concreto. Revista de Educação Matemática, São Paulo, v. 9, n. 9-10, p. 1- 6. 2005. Disponível em: https://www.revistasbemsp.com.br/REMatSP/article/view/76. Acesso em: 22 mar. 2021.

OLIVEIRA, M. M. Como fazer pesquisa qualitativa. 4. ed. Petrópolis: Vozes, 2012.

PARANÁ. Secretaria de Estado da Educação do Paraná. Diretrizes Curriculares de Matemática. Curitiba: SEED, 2008. Disponível em:

http://www.educadores.diaadia.pr.gov.br/arquivos/File/diretrizes/dce mat.pdf. Acesso em: 11 nov. 2020.

PARANÁ. Secretaria de Estado da Educação do Paraná. Os desafios da escola pública paranaense na perspectiva do professor PDE: produções didático-pedagógicas. Curitiba: SEED, 2013.

RODRIGUES, F. C.; GAZIRE, E. S. Reflexões sobre uso de material didático manipulável no ensino de Matemática: da ação experimental à reflexão. Revemat: Revista Eletrônica de Educação Matemática, Florianópolis, v. 7, n. 2, p. 187-196, 2012. DOI:

http://dx.doi.org/10.5007/1981-1322.2012v7n2p187.

SILVA, A. C. S.; SOUZA, J. K. C. Geoplano e o cálculo de área de figuras planas: reflexões de uma intervenção pedagógica. In: JORNADA DE ESTUDOS EM MATEMÁTICA, 2., 2016, Marabá, PA. Anais [...]. Marabá: Unifesspa, 2016. Disponível em:

https://jem.unifesspa.edu.br/images/2JEM/ANAIS/CC/O_geoplano_e_o clculo de rea.pdf.

Acesso em: 15 maio 2018.

SILVA, L. P. M. O que é geometria? Brasil Escola. Disponível em:

https://brasilescola.uol.com.br/o-que-e/matematica/o-que-e-geometria.htm. Acesso em: 12 nov. 2020.

ZAPPELLINI, M. B.; FEUERSCHÜTTE, S. G. O uso da triangulação na pesquisa científica brasileira em administração. Administração: Ensino \& Pesquisa, Rio de Janeiro, v. 16, n. 2, p. 241-273, abr./jun. 2015. DOI: https://dx.doi.org/10.13058/raep.2015.v16n2.238. 